\title{
A case report of brain abscess caused by Nocardia farcinica
}

\author{
Jiangqin Song ${ }^{1 \dagger}$, Lian Dong ${ }^{2+}$, Yan Ding ${ }^{3}$ and Junyang Zhou ${ }^{4^{*}}$
}

\begin{abstract}
Background: Brain abscess due to the Nocardia genus is rarely reported and it is usually found in immunocompromised patients. Treatment of Nocardia brain abscess is troublesome and requires consideration of the severity of the underlying systemic disease. The difficulties in identifying the bacterium and the frequent delay in initiating adequate therapy often influence the prognosis of patients.

Case presentation: Here, we report a rare case of brain abscess caused by Nocardia farcinica. The patient's medical history was complicated: he was hospitalized several times, but no pathogens were found. At last, bacteria were found in the culture of brain abscess puncture fluid; the colony was identified as Nocardia farcinica by mass spectrometry. Targeted antibiotic treatment was implemented, brain abscess tended to alleviate, but the patient eventually developed fungal pneumonia and died of acute respiratory distress syndrome (ARDS).

Conclusion: Brain abscess caused by Nocardia farcinica can appear in non-immunocompromised individuals. Early diagnosis, reasonable surgical intervention, and targeted antibiotic treatment are critical for Nocardia brain abscess treatment. In the treatment of Nocardia brain abscess, attention should paid be to the changes in patients'immunity and infection with other pathogens, especially fungi, avoided.
\end{abstract}

Keywords: Nocardia farcinica, Brain abscess, Case report

\section{Background}

Nocardia is an aerobic filamentous environmental Grampositive bacterium and is usually considered as an opportunistic pathogen, belonging to the order Actinomycetes [1]. Nocardia brain abscess is rare and typically found in immunocompromised patients [1]. Nocardia infections comprise only $2 \%$ of all intracranial abscesses [2], but overall mortality rate can exceed $20 \%[3,4]$. Brain abscess caused by Nocardia farcinica is rarely reported in clinical practice. The treatment is troublesome and the difficulties lie in the timely identification of the bacterium,

\footnotetext{
*Correspondence: 1466041119@qq.com

†Jiangqin Song and Lian Dong contributed equally to this work

${ }^{4}$ Department of Pathogen Biology and Immunology, Xuzhou Medical University, Xuzhou 221004, Jiangsu, China

Full list of author information is available at the end of the article
}

its inherent resistance to conventional antibiotics and the frequent delay in initiating an effective therapy $[5,6]$.

Here, we report a patient who suffered from brain abscess caused by Nocardia farcinica, although his condition improved after targeted antibiotic treatment, due to basic diseases and long-term use of antibiotics, he developed fungal infection in the lungs and eventually died of ARDS. This study hope to provide experience for the clinical diagnosis and treatment of Nocardia brain abscess.

\section{Case presentation}

A male aged 61 years was admitted to our hospital for intermittent fever and cough on August 16, 2019. In the past 4 years, the patient had developed pulmonary infection repeatedly, which improved after antiinfection treatment. He had a history of hypertension, coronary heart disease and bronchiectasis. In the past original author(s) and the source, provide a link to the Creative Commons licence, and indicate if changes were made. The images or other third party material in this article are included in the article's Creative Commons licence, unless indicated otherwise in a credit line to the material. If material is not included in the article's Creative Commons licence and your intended use is not permitted by statutory regulation or exceeds the permitted use, you will need to obtain permission directly from the copyright holder. To view a copy of this licence, visit http://creativecommons.org/licenses/by/4.0/. The Creative Commons Public Domain Dedication waiver (http://creativeco mmons.org/publicdomain/zero/1.0/) applies to the data made available in this article, unless otherwise stated in a credit line to the data. 
1 year, the patient intermittently developed cough, sputum, accompanied by fever, with a body temperature of about $38.0{ }^{\circ} \mathrm{C}$, without afternoon low fever, night sweats and hemoptysis. He was hospitalized for many times, no pathogens were detected during hospital stay. The patient continued to cough and fever intermittently outside the hospital.

On admission, the patient was conscious, with no enlargement of superficial lymph nodes, slightly coarse breathing sounds in both lungs, and a little moist crackles could be heard. On June 19, 2019, chest CT (computed tomography) indicated space occupation in the right upper lung, bilateral lung infective lesion with bronchiectasis, emphysema, bullae of the lung, right pleural effusion (Fig. 1A). On August 16, chest CT indicated that the lesion area of the right upper lung mass was significantly larger than before, accompanied by bronchiectasis, emphysema, and pulmonary bulla (Fig. 1B). After admission, the patient underwent CT-guided percutaneous lung puncture examination, and the tissues were subjected pathological examination and microbial culture. Histopathology showed chronic inflammatory changes accompanied by mild hyperplasia of alveolar epithelium. No bacteria were observed in lung tissue culture. Bronchoscope alveolar lavage fluid (BALF) examination revealed bronchial inflammation. Cytology of lavage fluid exfoliation: no cancer cells detected; mTB-DNA was not detected in BALF by Gene Xpert. No acid-fast bacilli were found in lavage fluid and sputum by acid-fast staining, and no hyphae and spores of bacteria and fungi were found by Gram stain. Mycobacterium culture was negative. IgA, IgG, IgM, C3 and C4 were normal. Blood tests for white blood cells (WBC) $13.6 \times 10^{9} / \mathrm{L}$ (reference range: $3.5-9.5 \times 10^{9} / \mathrm{L}$ ), C-reactive protein (CRP) $64.67 \mathrm{mg} / \mathrm{L}$ (reference range: $<6.0 \mathrm{mg} / \mathrm{L}$ ), PCT $0.053 \mathrm{mg} / \mathrm{L}$ (reference range: $0-0.046 \mathrm{ng} / \mathrm{mL}$ ).

After treatment with cefoperazone sodium + sulbactam sodium, the patient's symptoms (fever, cough and sputum) improved, but neurological symptoms such as headache, delirium and memory loss appeared on

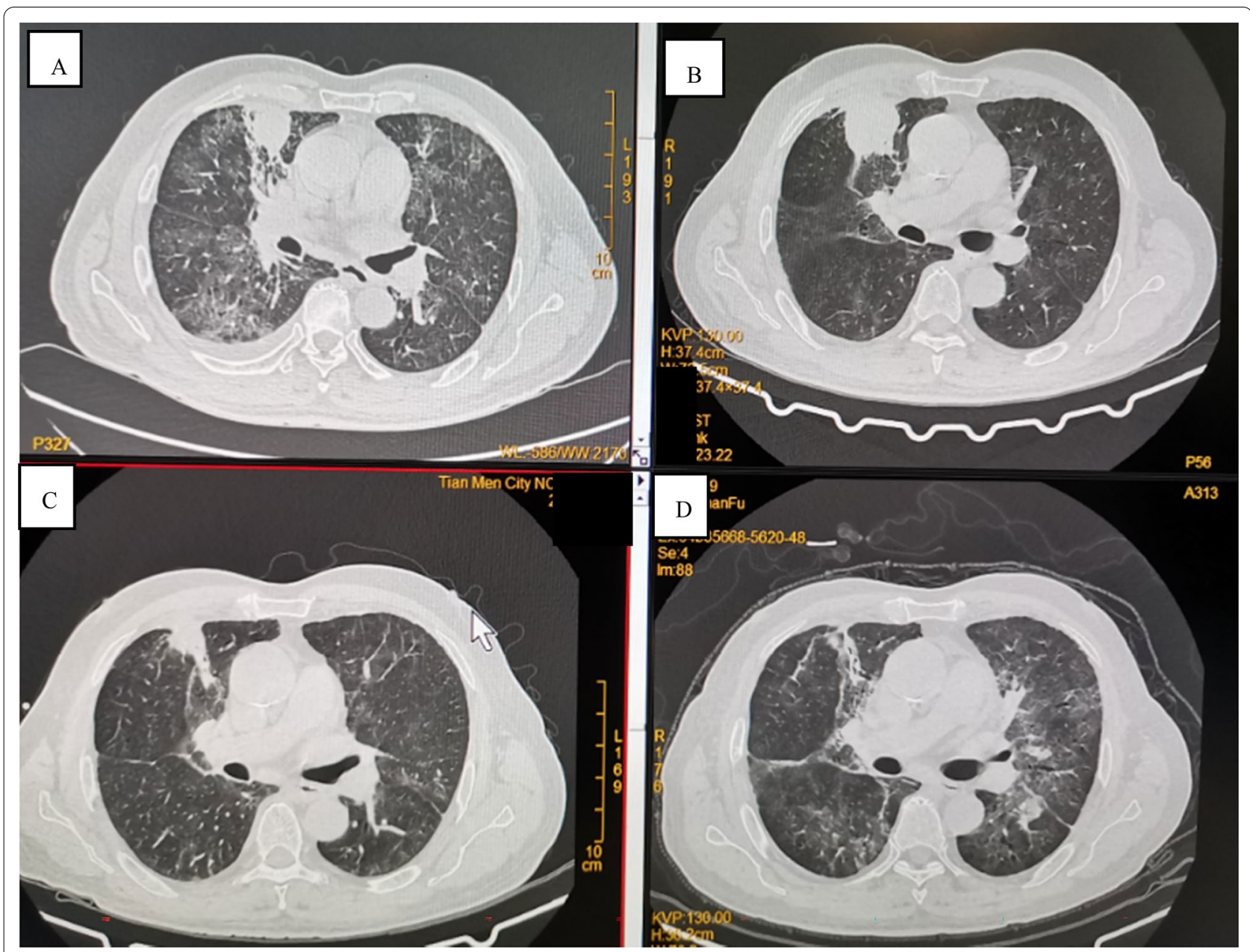

Fig. 1 Chest CT images of the patient. A Chest CT on June 19. B Chest CT August 16. C Chest CT on September 14. D Chest CT on December 9 
August 16. A magnetic resonance imaging (MRI) scan of the brain suggested space occupation in the left frontal lobe, the maximum cross-sectional area of the lesion was about $35 \mathrm{~mm} \times 52 \mathrm{~mm}$; brain abscess was considered (Fig. 2A). On August 28, the patient underwent minimally invasive puncture drainage under CT-guidance, and about $10 \mathrm{~mL}$ yellow purulent fluid was extracted. The puncture fluid was sent to the microorganism laboratory for testing, after 48-h culture, white cotton-like colonies grew (Fig. 3A-C). After smear staining, branching and uneven staining of filamentous bacilli could be seen under the microscope. The mycelia could be wound into clusters to form actinomycetes like particles, Gram stain and the weak acid-fast staining were positive (Fig. 3DF). The bacteria were identified as Nocardia farcinica by mass spectrometry, with $99.9 \%$ credibility. Then, the patient was diagnosed with Nocardia farcinica brain abscess. After 16 days of treatment with trimethoprim/ sulfamethoxazole (TMP/SMX) (3.0 g, po, bid) and intravenous amikacin $(0.4 \mathrm{~g}$, iv, $\mathrm{qd})$, the patient's temperature
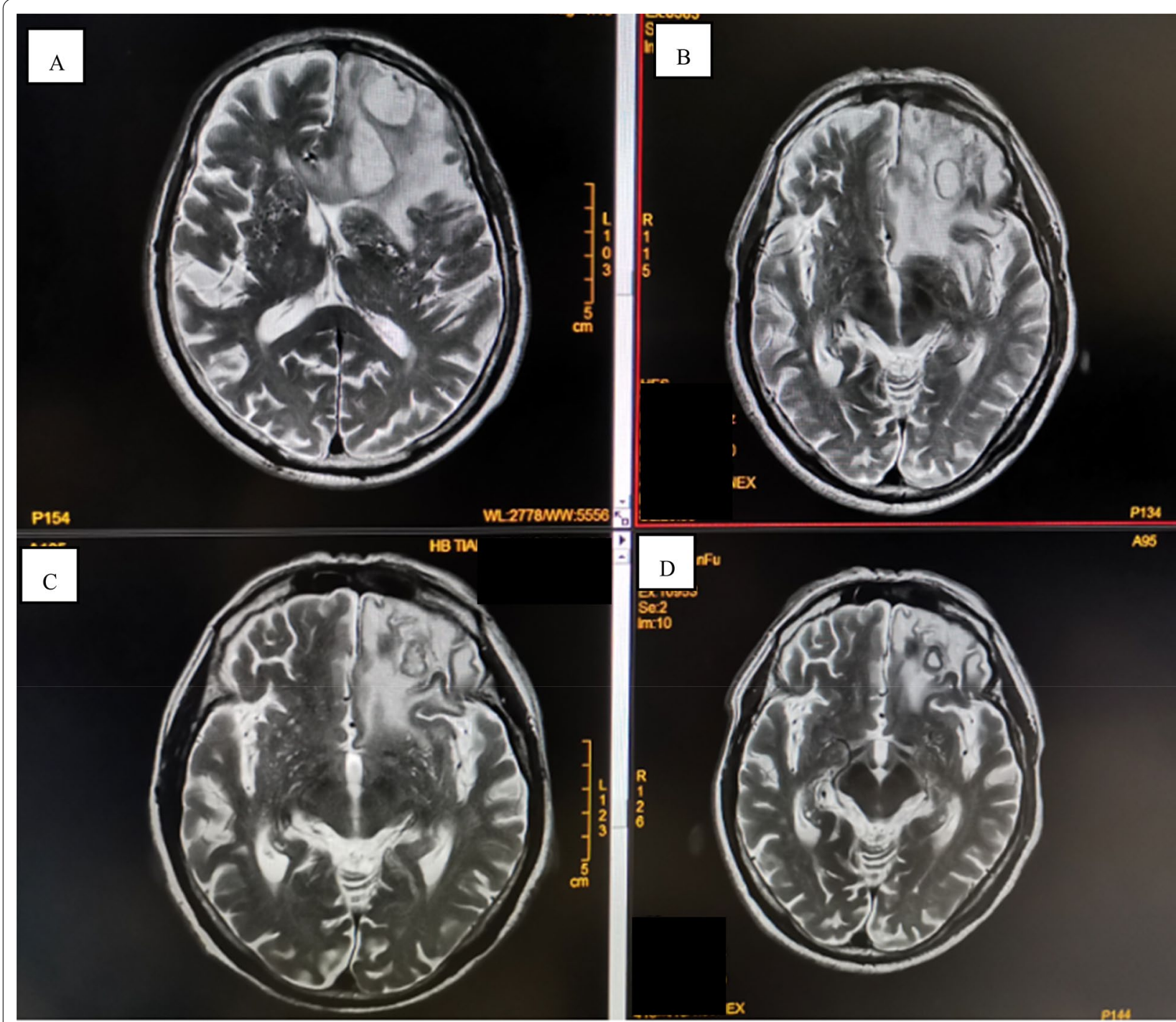

AcS

Fig 2 Brain MRI images of the patient. A Brain MRI on August 23. B Brain MRI September 14. C Brain MRI on October 22. D Brain MRI on November

(See figure on next page.)

Fig. 3 Culture and staining of Nocardia farcinica. A Images of puncture fluid after 48 h of culture. B Images of puncture fluid after 72 h of culture. C Images of pure bacteria after $24 \mathrm{~h}$ of culture. D Gram stain of Nocardia farcinica. E Acid-fast staining of Nocardia farcinica. F Weak acid-fast staining of Nocardia farcinica 

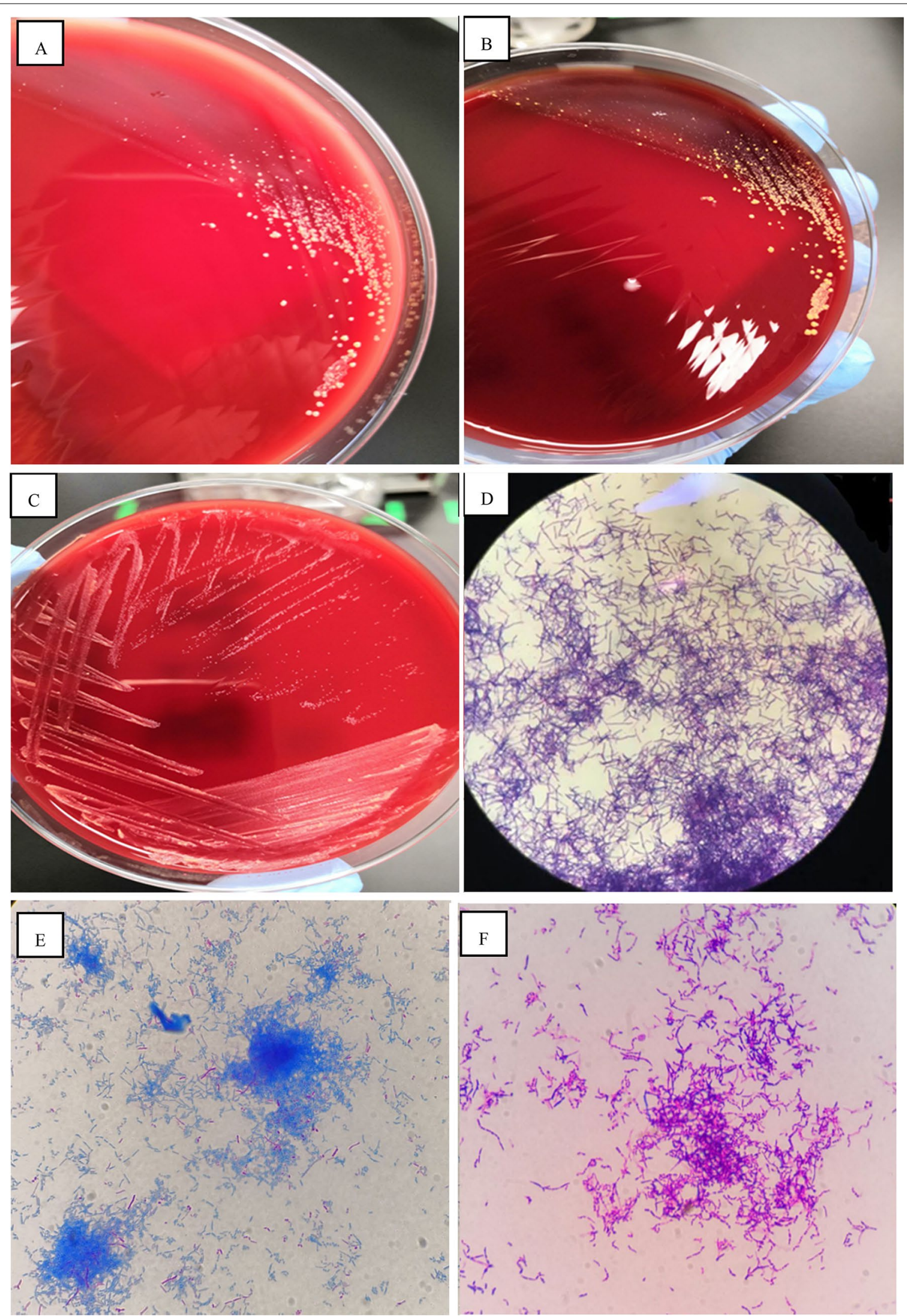

Fig. 3 (See legend on previous page.) 
returned to normal and his headache completely disappeared, intracranial mass was significantly reduced (Fig. 2B) and the right upper lung mass was significantly absorbed (Fig. 1C). During subsequent treatment, the patient developed nausea and vomiting for many times, which was considered to be caused by cerebral edema. After treatment with mannitol dehydration, the symptoms were relieved. Re-examination of head MRI on October 23 (Fig. 2B) showed that the brain abscess lesions were smaller than before, the brain edema was significantly better than before. The previous anti-infection treatment regimen was continued.

On December 8, the patient had occasional mild chest tiredness, which relieved spontaneously, intermittent cough, nausea and retching, chest CT showed significant increase in lung lesions, partial bronchiectasis, emphysema and bullous lungs appeared (Fig. 1D). The patient developed dyspnea on December 12 accompanied by wheezing sound in both lungs, sputum culture suggested Candida tropicalis. The patient was given antifungal and antiasthmatic treatment with itraconazole and doxotheophylline. On December 15, he developed ARDS, blood pressure (BP): 100/75 mmHg, arterial blood oxygen saturation $\left(\mathrm{SaO}_{2}\right) 79 \%$. After a series of treatments, including assisted respiration (mask oxygen inhalation), anti-inflammatory (methylprednisolone), antiasthmatic (doxophylline, salbutamol, ipratropium bromide), hyperensort (dopamine), the patient's dyspnea symptoms were not relieved and blood pressure did not rise (BP $77 / 52 \mathrm{mmHg}$ ). The patient's family gave up the rescue. Subsequently, the patient went into a deep coma, lost consciousness, and the heart rate dropped. The patient died on the morning of the 16th, and the family refused an autopsy.

\section{Discussion and conclusion}

Nocardia is a soil-borne strictly aerobic actinomycete with at least 16 species that can affect human health [7]. Nocardia spp. have a predilection for the lungs and brain as foci of infection, particularly in immunocompromised hosts [8]. In this case, the patient was a 61-year-old male with no immunodeficiency disease, but he had bronchiectasis, hypertension, coronary heart disease. Multiple lung infections, 11 hospitalizations, and prolonged antibiotic use in the past 5 years may be the key factors in the patient's Nocardia infection.

Nocardia farcinica was the most common species in Nocardia infection, accounting for 24.5\% [9]. Nocardia farcinica is more prone to affect the central nervous system (CNS) than other species [10,11]. Clinical manifestations of CNS nocardiosis usually result from local effects of granulomas or abscesses in the brain, less commonly in the spinal cord or meninges $[10,11]$. The abscess usually can be identified by CT scan or MRI as a ring enhancement at the capsular phase [12], but needs to be distinguished from tumor, cystic or necrotic foci [13]. In our case, after the patient developed symptom of headache, brain abscess was found by MRI examination. Patient underwent minimally invasive surgery for intracranial abscess puncture and suction under CT-guidance, smear staining and bacterial culture were performed on the drainage fluid, and the cultivated colonies were identified as Nocardia farcinica by mass spectrometry.

Nocardia identification can be difficult because of the slowly growing pattern of the germ and low positive rate (colonies usually require at least $48 \mathrm{~h}$ of incubation although more commonly 3 to 5 days and up to 14 to 21 days), preferably in selective media [14]. To isolate Nocardia spp., multiple cerebrospinal fluid (CSF) specimens should be cultured to increase the yield, although it is not uncommon for the bacteria to be recovered only when direct pus is cultured [15]. Certain laboratory techniques like mass spectrometry may help to identify the genus and species. The preferred methods for test of Nocardia are 16S rRNA gene analysis and other molecular techniques, such as restriction fragment length polymorphisms and multilocus sequence analysis. Direct abscess drainage seems to be the best method for collection of samples for microbiological confirmation and antibiotic susceptibility testing [16]. Nocardia pneumonia often requires bronchoscopy or percutaneous lung biopsy, and a detailed history and thorough physical examination should be taken to adequately assess the presence of spread of the lesions. Cranial CT or MRI should be performed if symptoms or signs suggest intracranial involvement. The patient was considered to have a pulmonary infection caused by inhalation of the bacterium through the respiratory tract and a cerebral abscess caused by haematogenous spread to the brain. In our case, the patient's repeated sputum culture and BALF tests showed no bacterial growth. Test was negative in the first percutaneous lung biopsy tissue culture, possibly because no valuable lesion tissue was collected at the biopsy site or the use of antibiotics affected the detection rate. This also suggests that Nocardia is more difficult to identify than more common bacteria. Bacterial grew after $24 \mathrm{~h}$ of culture of puncture fluid, indicating a severe brain infection and suggested that abscess drainage may be good for isolating and culturing Nocardia.

Direct smears from surgical samples show Grampositive, beaded, branching filaments that are partially acid-fast, and thus need to be differentiated from mycobacteria. Colonies usually have a chalky white cotton-like appearance because of the abundant aerial filaments. The smell of moist or wet soil is very characteristic of Nocardia spp. colonies [4]. Nocardia spp. 
exhibit variable morphologic appearances depending on the species, the incubation conditions and the duration of incubation. In routine culture media, Nocardia spp. appears as bacilli with ramifications and sub-ramifications at right angles that may form coccus in thioglycolate medium after prolonged incubation [7]. The colonies we obtained from the puncture fluid were positive for Gram staining and weak acid resistance for acid-fast staining (Fig. 3D-F). The characteristics of bacterial culture and growth (Fig. 3A-C) are consistent with the above literature reports.

Nocardia farcinica brain abscess has a high mortality rate, as high as $20 \%$ in immunocompetent patients and $55 \%$ in immunocompromised patients. These high rates are attributed to the severity of underlying disease, difficulties in identifying the pathogen, and its inherent resistance to antibiotics, leading to inappropriate or late initiation of therapy [5]. In a study of Nocardia isolated from human samples in France, $N$. farcinica was the most frequently isolated species in blood cultures and brain abscesses $(21 / 39,54 \%$ and $19 / 43,44.2 \%$, respectively. In the French data, $N$. farcinica was frequently not susceptible to cefotaxime ( $80 \%$ of the isolates), meropenem (73\% of isolates) and aminoglycosides (more than 90\%) [17]. Taking into account the inherent resistance of Nocardia farcinica to third-generation cephalosporins, TMP/SMX's ability to cross the blood-brain barrier, most authorities recommend TMP/SMX as part of firstline therapy for nocardiosis $[18,19]$. Abscesses $>25 \mathrm{~mm}$ in diameter and that fail to shrink after 4 weeks of antibiotic therapy should be aspirated to confirm the diagnosis regardless of the immune status of the patient [5]. Empiric treatment of cerebral nocardiosis is well established with the use of parenteral TMP/SMX, amikacin, and imipenem-cilastatin [20,21]. Recently, extendedspectrum fluoroquinolones such as moxifloxacin have been used successfully against $N$. farcinica cerebral abscess [22]. Because of its ability to cross the bloodbrain barrier, TMP/SMX is the treatment of choice and may be effective even when in vitro studies show resistance [20,23-25]. The abscesses in our patient's brain was about $35 \mathrm{~mm} \times 52 \mathrm{~mm}$, far more than $25 \mathrm{~mm}$, minimally invasive puncture drainage is of great significance for the identification of pathogenic bacteria and the treatment of patients. After 16 days of treatment with TMP/SMX, the patient's condition was significantly improved, the lesions in lung and head were also significantly reduced, show a good clinical response (Figs. $1 \mathrm{C}$ and $2 \mathrm{C}$ ). This also suggests that the lung lesions were caused by Nocardia farcinica.

When the patient was identified with Nocardia infection, the lung lesions and brain abscesses were very severe, which affected the patient's prognosis. After
2 months of continuous antibiotic treatment, the patient suddenly developed dyspnea, an acute outbreak of pulmonary fungal infection (Fig. 1D), laboratory tests identified the pathogen as Candida tropicalis, which is also an opportunistic pathogen. The patient developed repeated lung infections, merge a variety of basic diseases, long-term use of many kinds of antibiotics, with low immunity; all these factors may cause patients to have severe fungal infections at the latest stage of treatment. After routine use of antifungal drug, the disease deteriorated and oxygen saturation decreased, eventually resulting in death from ARDS.

In conclusion, brain abscess can be caused by Nocardia farcinica in non-immunocompromised individuals and it rarely occurs in clinical. In our case, although the patient's condition improved after targeted antibiotic treatment (TMP/SMX), due to underlying diseases and long-term use of antibiotics, the central nervous system symptoms appeared lately and delayed diagnosis, the patient eventually died. For pneumonia of unknown cause, a variety of technical means should be used to determine the pathogen as soon as possible: instituting targeted treatment, paying attention to the examination of the brain and other organs. Minimally invasive puncture drainage is of great significance for the diagnosis and treatment of Nocardia brain abscess. Because the treatment of Nocardia brain abscess requires longterm use of antibiotics, attention should be paid to the changes in patients' immunity and infection with other pathogens, especially fungi, avoided. Early diagnosis and targeted antibiotic treatment are critical for Nocardia brain abscess treatment and prognosis.

\section{Abbreviations}

ARDS: Acute respiratory distress syndrome; CT: Computed tomography; MRI: Magnetic resonance imaging; BALF: Bronchoscope alveolar lavage fluid; BP: Blood pressure; $\mathrm{SaO}_{2}$ : Arterial blood oxygen saturation; CNS: Central nervous system; CSF: Multiple cerebrospinal fluid.

\section{Acknowledgements}

Not applicable.

\section{Authors' contributions}

JS and JZ contributed to thesis selection and design, data collection; LD participated in data analysis and interpretation; YD contributed to critical review of the intellectual content of this article; JZ contributed to the manuscript writing. All authors read and approved the final manuscript.

\section{Funding}

The present study was supported by National Natural Science Foundation of China (NO. 81602297), Guangxi Zhuang Autonomous Natural Science Foundation (NO. 2018JJB140322). Funder YD contributed to critical review of the intellectual content of this article and gave financial support.

Availability of data and materials

All data are included in this article. 


\section{Declarations}

\section{Ethics approval and consent to participate}

Written informed consent was obtained from the patient's daughter for the publication of this case report.

\section{Consent for publication}

Written informed consent was obtained from the patient's daughter for publication of this case report and any accompanying images. A copy of the written consent is available for review by the Editor of this journal.

\section{Competing interests}

The authors declare that they have no competing interests.

\section{Author details}

${ }^{1}$ Laboratory Department, The First People's Hospital of Tianmen City, Tianmen 431700, Hubei, China. ${ }^{2}$ Oncology Department, The First People's Hospital of Tianmen City, Tianmen 431700, Hubei, China. ${ }^{3}$ Hubei Key Laboratory of Embryonic Stem Cell Research, Hubei University of Medicine, Shiyan 442000, Hubei, China. ${ }^{4}$ Department of Pathogen Biology and Immunology, Xuzhou Medical University, Xuzhou 221004, Jiangsu, China.

Received: 18 June 2021 Accepted: 23 July 2021

Published online: 03 August 2021

\section{References}

1. Fatahi-Bafghi M. Nocardiosis from 1888 to 2017. Microb Pathog 2018;114:369-84.

2. Grond SE, Schaller A, Kalinowski A, Tyler KA, Jha P. Nocardia farcinica brain abscess in an immunocompetent host with pulmonary alveolar proteinosis: a case report and review of the literature. Cureus. 2020;12(11):e11494.

3. Kumar VA, Augustine D, Panikar D, Nandakumar A, Dinesh KR, Karim S, Philip R. Nocardia farcinica brain abscess: epidemiology, pathophysiology, and literature review. Surg Infect (Larchmt). 2014;15(5):640-6.

4. Corti ME, Villafañe-Fioti MF. Nocardiosis: a review. Int J Infect Dis. 2003;7(4):243-50.

5. Mamelak AN, Obana WG, Flaherty JF, Rosenblum ML. Nocardial brain abscess: treatment strategies and factors influencing outcome. Neurosurgery. 1994;35(4):622-31.

6. Wilson JW. Nocardiosis: updates and clinical overview. Mayo Clin Proc 2012:87(4):403-7.

7. Sabuncuoğlu H, Cibali AZZ, Caydere M, Ustün H, Semih KI. Nocardia farcinica brain abscess: a case report and review of the literature. Neurocirugia (Astur). 2004;15(6):600-3.

8. Restrepo A, Clark NM. Nocardia infections in solid organ transplantation: guidelines from the Infectious Diseases Community of Practice of the American Society of Transplantation. Clin Transplant. 2019;33(9):e13509.

9. Huang L, Chen X, Xu H, Sun L, Li C, Guo W, Xiang L, Luo G, Cui Y, Lu B. Clinical features, identification, antimicrobial resistance patterns of Nocardia species in China: 2009-2017. Diagn Microbiol Infect Dis. 2019;94(2):165-72.

10. Peters BR, Saubolle MA, Costantino JM. Disseminated and cerebral infection due to Nocardia farcinica: diagnosis by blood culture and cure with antibiotics alone. Clin Infect Dis. 1996;23(5):1165-7.

11. Miralles GD. Disseminated Nocardia farcinica infection in an AIDS patient Eur J Clin Microbiol Infect Dis. 1994;13(6):497-500.
12. Moorthy RK, Rajshekhar V. Management of brain abscess: an overview. Neurosurg Focus. 2008;24(6):E3.

13. Zhu JW, Zhou H, Jia WQ, You J, Xu RX. A clinical case report of brain abscess caused by Nocardia brasiliensis in a non-immunocompromised patient and a relevant literature review. BMC Infect Dis. 2020;20(1):328.

14. Pascual-Gallego M, Alonso-Lera P, Arribi A, Barcia JA, Marco J. Nocardia farcinica abscess of the cerebellum in an immunocompetent patient: a case report and review of the literature. Asian J Neurosurg. 2016;11(4):454.

15. Chow FC, Marson A, Liu C. Successful medical management of a Nocardia farcinica multiloculated pontine abscess. BMJ Case Rep. 2013. https://doi. org/10.1136/bcr-2013-201308.

16. Galacho-Harriero A, Delgado-López PD, Ortega-Lafont MP, Martín-Alonso J, Castilla-Díez JM, Sánchez-Borge B. Nocardia farcinica brain abscess: report of 3 cases. World Neurosurg. 2017:106:1015-53.

17. Lebeaux D, Bergeron E, Berthet J, Djadi-Prat J, Mouniée D, Boiron P, Lortholary O, Rodriguez-Nava V. Antibiotic susceptibility testing and species identification of Nocardia isolates: a retrospective analysis of data from a French expert laboratory, 2010-2015. Clin Microbiol Infect. 2019;25(4):489-95.

18. Budzik JM, Hosseini M, Mackinnon AJ, Taxy JB. Disseminated Nocardia farcinica: literature review and fatal outcome in an immunocompetent patient. Surg Infect (Larchmt). 2012;13(3):163-70.

19. Viganò SM, Edefonti A, Ferraresso M, Ranzi ML, Grossi P, Righini A, Rusconi $R$, Santambrogio L, Ghio L. Successful medical treatment of multiple brain abscesses due to Nocardia farcinica in a paediatric renal transplant recipient. Pediatr Nephrol. 2005;20(8):1186-8.

20. Brown-Elliott BA, Brown JM, Conville PS, Wallace RJ. Clinical and laboratory features of the Nocardia spp. based on current molecular taxonomy. Clin Microbiol Rev. 2006;19(2):259-82.

21. Fellows GA, Kalsi PS, Martin AJ. Nocardia farcinica brain abscess in a patient without immunocompromise. Br J Neurosurg. 2007;21(3):301-3.

22. Miksits K, Stoltenburg G, Neumayer HH, Spiegel H, Schaal KP, CervósNavarro J, Distler A, Stein H, Hahn H. Disseminated infection of the central nervous system caused by Nocardia farcinica. Nephrol Dial Transplant. 1991;6(3):209-14

23. Delvenne E, Farnir F, Guiot J, Giot JB, Von Frenckell C. Brain abscesses associated with a systemic infection by Nocardia farcinica. Rev Med Liege. 2017:72(7-8):340-3.

24. Lin YJ, Yang KY, Ho JT, Lee TC, Wang HC, Su FW. Nocardial brain abscess. J Clin Neurosci. 2010;17(2):250-3

25. Buelte D, Noth J, Mull M, Sellhaus B, Koch A, Queider M, Hünger F, Gobbelé $R$. Different manifestations of the cerebral nocardiosis. Nervenarzt. 2008;79(12):1432-5.

\section{Publisher's Note}

Springer Nature remains neutral with regard to jurisdictional claims in published maps and institutional affiliations. 